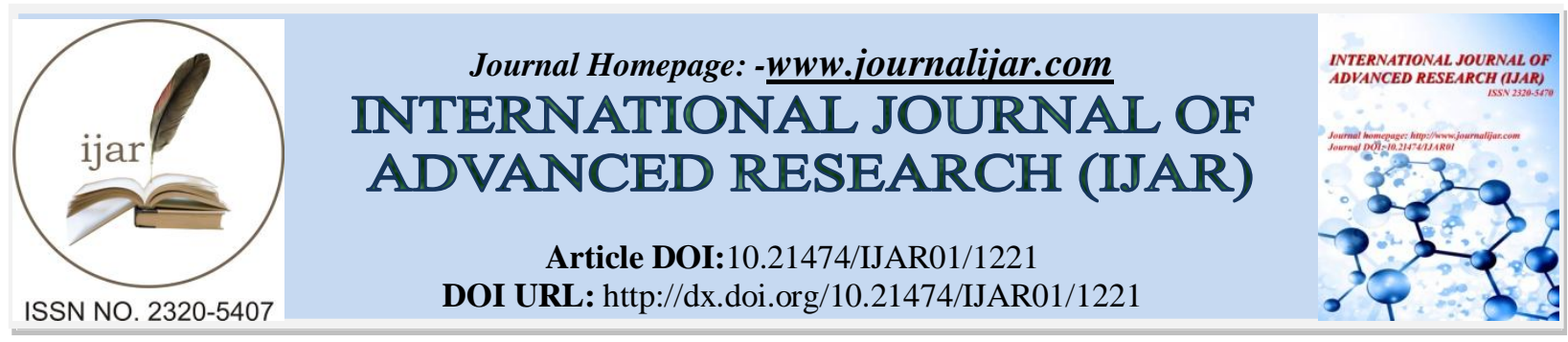

RESEARCH ARTICLE

\title{
REDUCING SLUDGE VOLUME IN PIT LATRINES: CAN LATRINE ADDITIVES IN GHANA HELP?
}

*Eric Awere andK. B. M. Edu-Buandoh.

Department of Civil Engineering, Cape Coast Polytechnic, Cape Coast, Ghana.

\section{Manuscript Info}

(..........................

Manuscript History

Received: 12 June 2016

Final Accepted: 22 July 2016

Published: August 2016

Key words:-

Faeces, Pit Latrine Additives,

Biodegradability,

COD.

\section{Abstract}

Public latrines are patronized by more than $34 \%$ of the Ghanaian population. With high usage rate, the pits get full quickly requiring frequent desludging. One of the solutions for dealing with full pits is the use of pit latrine additives but studies have produced variable results. This research assessed excreta degradability and efficacy of pit latrine additives in Cape Coast. Homogenous fresh faeces were taken from three public pit latrines for characterization and additives study. The efficacy of two commercial additives and household ash were tested at the laboratory for 30days at ambient temperature $\left(22^{\circ} \mathrm{C}\right)$ under aerobic conditions. For each trial, three different treatments (control, water and additives) were studied. The results show that the soluble COD, particulate COD, moisture content and organic solids content were respectively $0.04-0.08 \mathrm{mg} / \mathrm{mg}$ dry sample, $0.10-0.24 \mathrm{mg} / \mathrm{mg}$ dry sample, $70-76 \%$ dry sample and $71-76 \%$ dry sample for all the three pits before additives application. All the samples recorded a reduction in the characteristics after additives application except for Additive B which recorded an increase. The mass of waste in each unit decreased with time over the 30days after applying the additives. Except for additive B $(2.6 \%$ and $4.1 \%)$, all the other treatments recorded a net mass loss of $5.6 \%-7.7 \%$ of their original mass. However, additives $\mathrm{A}$ and $\mathrm{C}$ did not have any significant effect on the physico-chemical characteristics and degradation rate of the fresh faeces.

Copy Right, IJAR, 2016,. All rights reserved.

\section{Introduction:-}

Developing and developed countries alike are faced with the problem of human excreta management particularly in the urban and peri-urban areas. Latrines are provided to ensure hygienic separation of faeces from human contact. In all cases, the containment system of the toilet block holds the excreta temporarily or provides the needed environment for partial or full decomposition of the excreta. Once the containment system gets full, desludging becomes a problem for users. The high cost of emptying coupled with the long waiting time between the pit filling up and an emptying service being acquired forces users to resort to other means of excreta disposal which may not be improved. 
The potential of pit latrine additives in reducing sludge volume has been on the forefront of various debates on ways of dealing with full pits. Various suppliers and manufacturers of additives claim that pit latrine additives have the potential of reducing sludge volume in pit latrines (Bakare et al., 2010). Studies conducted to test the effectiveness of pit latrine additives have revealed variable results (Thye et al., 2009).

The amount of biodegradable or non-biodegradable material present in a pit latrine determines the efficacy of latrine additive added to it (Bakare et al., 2010).Many literature reports that between $70 \%$ to $80 \%$ of human faeces is water while the remaining 20\% - 30\% is solid matter (Foxon, 2007; Jansen et al., 1993; Stephen \&Cummin, 1980, Torondel, 2010). The solid content of faeces consists of 30\% dead bacteria, $30 \%$ indigestible food matter such as cellulose whiles the remaining $40 \%$ is made up of fats, inorganic substances such as calcium, phosphate and protein in various proportions (http://www.britannica.com/EBchecked/topic/203293/feces). Foxon (2007) and Zavala et al. (2002), (2004) reports that as high as $80 \%$ of organic material in faeces to be biodegradable. Other literature relates the amount of volatile solids to organic matter content in faeces. From various literature values reported on faecal sludge, Doku (2002) found total volatile solids constitute over 50\% of total solids indicating high organic content of faecal sludge.

Little research has been undertaken in determining the efficacy of pit latrine additives both at the laboratory scale and through field trials. Studies on effectiveness of pit latrine additives by Bakare et al. (2010) was carried out at the laboratory (30days incubation period) and through field trials (3 months duration) on sixteen (16) pit latrines located in eThekwini Municipality, South Africa. Although there was mass loss in both trials due to treatment with commercial additives, the reduction was concluded to be statistically insignificant. In another study (Foxon et al., 2009), two laboratory trials were carried out to test the efficacy of commercial pit latrine additive in reducing sludge content in pit latrines. In trial 1 , the effect of aerobic and anaerobic conditions was tested. The treatments were incubated for 46 days in a fume cupboard and no water reference units were constructed for the anaerobic set. In trial 2, the relative humidity of the air supply for aerobic tests was increased to reduce dehydration. Two reference treatments/ controls were included for comparative purposes, namely no addition of water or chemicals (control); or addition of water (water reference). Only 3 replicates were used for each treatment in the second trial and the trial was terminated after 27 days. The study revealed that the treatment of pit-latrine contents with commercial pitlatrine additives had no statistically significant effect on the rate of mass loss of pit-latrine contents under both aerobic and anaerobic conditions. A study was conducted in Uganda with support from UNICEF to find alternative options of reducing the frequency of pit emptying. In this study, Effective Micro-organisms (EMO) which enhances breakdown of organic matter was used. EMO were reported to be non-genetically-engineered, non-pathogenic, nonharmful and non-chemically synthesized. The experiment was carried out on school pit latrines that were found to be filling up faster. Within three (3) weeks of the experiment, there was a substantial reduction in stench and sludge volume with approximately 26.05 metres of the pit space recovered in 16 primary schools. Relatively, more sludge reduction was observed in latrines with fresh plant-based anal cleansing materials than paper. In addition, substantial sludge reduction was seen in latrines used by boys than girls because of increased uric acid from urine (girls' latrines were used for both urination and defaecation) which is harmful to EMOs (Bwengye-Kahororo et al., 2013).

This research, therefore seeks to assess the excreta degradation and efficacy of commercial pit latrine additives in improving the degradation rate of public pit latrines in Cape Coast, Ghana.

\section{Material and Methods:-}

\section{Sampling Points and Procedure:-}

Three (3) different public pit latrines located in three different areas were selected for the study. Samples of fresh faeces of approximately 1 Litre were collected from each of the three (3) selected latrines. The fresh faeces were collected from the surface early in the morning when majority of the users were expected to use the facility. For each latrine, samples were randomly taken from five (5) different locations in the pit and thoroughly mixed to obtain composite samples. The physico-chemical characteristics (COD, moisture and solids content) were determined on the fresh faeces before and after addition of additives.

\section{Sample Preservation Techniques:-}

To imitate the dark environment of the pit and to ensure that the bio-activity of the samples is not altered, samples were wrapped in black polythene bags before transporting them to the laboratory. All samples were stored in a cold environment at $4^{\circ} \mathrm{C}$ and allowed to reach room temperature before use in the laboratory. Tests were carried out within 24 hours of sampling. 


\section{Description of Pit latrine additives:-}

Two (2) different commercial latrine additives and household ash were selected for this study. The additives are identified as Product $\mathrm{A}-\mathrm{C}$. The description of each product used is presented in Table 1 .

Table 1:- List of additives used in this study and their description.

\begin{tabular}{|c|c|l|}
\hline Product & Product Name & Description \\
\hline A & Household Ash & $\begin{array}{l}\text { This product is household ash from charcoal usage. Some authors } \\
\text { Agyei et al., 2011; Morgan, 2005) report that ash have been used to } \\
\text { prevent odour and reduce the volume of sludge in pit latrines }\end{array}$ \\
\hline B & Acidic Disinfectant & $\begin{array}{l}\text { There was no definite description given by the manufacturer but the } \\
\text { product is a green liquid. The manufacturer claims that the product } \\
\text { prevents odour, flies, insects and reduce sludge volume in pit latrines } \\
\text { within 2 weeks of application. }\end{array}$ \\
\hline C & Septonic & $\begin{array}{l}\text { The manufacturer claims that the product contains enzymes, yeast, } \\
\text { organic solids, water conditioner and it reduces sludge volume in septic } \\
\text { tanks and pit latrines. The additive is in pellets form. }\end{array}$ \\
\hline
\end{tabular}

\section{Dosage of Additives Applied:-}

The dosage of the various additives used in the study were applied according to Eqn. 1 . A honey jar of surface area 5 $\mathrm{mm}^{2}$ was used. Additive A was dosed based on researcher's own intuition.

$$
\operatorname{Doseapplied}(\mathrm{ml})=\frac{\text { manufacturer'sdosage }(\mathrm{ml}) x \operatorname{surfaceareaofhoneyjar}\left(\mathrm{mm}^{2}\right)}{\text { surfaceareaofpitlatrine }\left(\mathrm{mm}^{2}\right)} \ldots \ldots \ldots \text { (Eq. 1) }
$$

\section{Experimental Methods:-}

Efficacy of pit latrine additives:-

The laboratory protocol for testing the efficacy of pit latrine additives devised by Buckley et al. (2008) was adopted for this study. Experiments were conducted at ambient temperature $\left(22^{\circ} \mathrm{C}\right)$ under aerobic conditions (the additives are applied to the top layer of the pit latrine, an aerobic zone). For each trial, a number of treatments were investigated.

1. Control: Units containing only pit latrine sample acting as controls.

2. Water treatment: Water was added to these units to quantify the effects of dilution, suspension and water transport on the trials in the absence of other chemical and biological additives.

3. Additive treatments: Additives were added to test units on per area basis.

Three replicates were prepared for each treatment. The mass of the honey jars were measured when empty, immediately after filling and at intervals of approximately 3 days for 30 days after commencement of the experiment. The time frame for this study is approximately equal to that conducted by Bakare et al. (2010), Buckley et al. (2008) and Bindoff (2008) and considered to be appropriate.

\section{Characterization of fresh faeces and pit latrine sludge:-}

Pit latrine material were characterized before and after application of pit latrine additive to provide back-up information to determine the underlying cause of test observations. The physico-chemical properties measured are listed in Table 2.

Table 2:-Parameters used to measure physico-chemical properties of fresh faeces and pit latrine faecal sludge.

\begin{tabular}{|l|l|}
\hline Parameter & Reason for inclusion \\
\hline Moisture & To quantify the moisture content of sample \\
\hline Total solids & $\begin{array}{l}\text { As a step to determine moisture content, and organic solids. } \\
\text { To eliminate variation in COD value, as a result of dilution effect of different } \\
\text { moisture contents when quantifying COD of samples. }\end{array}$ \\
\hline Organic solids & To quantify the organic material present in the samples \\
\hline Inorganic solids & To estimate the non-biodegradable fraction of the total solids \\
\hline Total COD (tCOD) & To measure oxidisable organic matter in the different samples \\
\hline $\begin{array}{l}\text { Soluble Chemical Oxygen } \\
\text { demand (sCOD) }\end{array}$ & To quantify dissolvable oxidisable organic matter \\
\hline $\begin{array}{l}\text { Particulate chemical oxygen } \\
\text { demand (pCOD) }\end{array}$ & To quantify particulate oxidisable organic matter \\
\hline
\end{tabular}


Sample preparation and testing for COD (total, soluble and particulate), solids and moisture content. The COD fractionation test followed the protocol used by Nwaneri, 2009 and Nwaneri et al., 2008. The fractionated COD (tCOD, sCOD and pCOD), Solids (Total and volatile) and moisture content of samples were measured using the open reflux method according to Standard Analytical Methods (APHA, AWWA \& WEF, 1999).

\section{Result and Discussion:-}

Physico-chemical properties of fresh faeces before adding additives:-

The average results of the physico-chemical characteristics of fresh faeces obtained from the surface of the three pits latrines together with the $95 \%$ confidence interval are presented in Table 3.The average moisture content values measured in the three pits show that between $70-76 \%$ of the faeces sampled from the surface of the pit is water. Various literature values for moisture content of fresh faeces are within the range of $50-90 \%$ (Foxon, 2007; Strauss, 1985). Values reported by Strauss (1985) shows that as high as $92 \%$ of human faeces are rich in organic matter that can be biodegraded. In addition, Foxon (2007) has reported that as high as $80 \%$ of the organic matter in faeces is biodegradable. The high percentage of organic solids $(71-76 \%$ dry sample) recorded in this study therefore indicates that faeces are high in organic matter that can be biodegradable and contains less inorganic materials (24-29\% dry sample) and are consistent with literature values (Doku, 2002).

Table 3:- Mean physico-chemical characteristics of fresh faeces for the three pit latrines before the additives application

\begin{tabular}{|c|c|c|c|c|c|c|c|c|c|c|}
\hline \multirow[t]{2}{*}{ Parameter } & \multirow[t]{2}{*}{$\begin{array}{l}\text { Pit } \\
\text { No. }\end{array}$} & \multirow[t]{2}{*}{$\mathrm{N}$} & \multirow[t]{2}{*}{ Mean } & \multirow[t]{2}{*}{ Std. Dev. } & \multirow[t]{2}{*}{$\begin{array}{l}\text { Std. } \\
\text { Error }\end{array}$} & \multicolumn{2}{|c|}{$\begin{array}{l}95 \% \text { Confidence } \\
\text { Interval for Mean }\end{array}$} & \multirow[t]{2}{*}{$\begin{array}{l}\text { Minim } \\
\text { um }\end{array}$} & \multirow[t]{2}{*}{$\begin{array}{l}\text { Maxim } \\
\text { um }\end{array}$} & \multirow[t]{2}{*}{$\begin{array}{c}\mathrm{C} \text { of } \mathrm{V} \\
\%\end{array}$} \\
\hline & & & & & & $\begin{array}{l}\text { Lower } \\
\text { Bound }\end{array}$ & $\begin{array}{l}\text { Upper } \\
\text { Bound }\end{array}$ & & & \\
\hline \multirow{3}{*}{$\begin{array}{l}\text { Total COD } \\
\text { (mg/mg dry } \\
\text { sample) }\end{array}$} & 1 & 3 & 0.2494 & 0.07295 & 0.04212 & 0.0682 & 0.4306 & 0.18 & 0.33 & 29.3 \\
\hline & 2 & 3 & 0.2465 & 0.04574 & 0.02641 & 0.1329 & 0.3601 & 0.20 & 0.29 & 18.6 \\
\hline & 3 & 3 & 0.2026 & 0.06593 & 0.03807 & 0.0388 & 0.3664 & 0.14 & 0.27 & 32.5 \\
\hline \multirow{3}{*}{$\begin{array}{l}\text { Soluble COD } \\
\text { (mg/mg dry } \\
\text { sample) }\end{array}$} & 1 & 3 & 0.0590 & 0.02523 & 0.01457 & -0.0037 & 0.1217 & 0.03 & 0.08 & 42.8 \\
\hline & 2 & 3 & 0.0568 & 0.01760 & 0.01016 & 0.0131 & 0.1005 & 0.04 & 0.07 & 31.0 \\
\hline & 3 & 3 & 0.0492 & 0.01909 & 0.01102 & 0.0017 & 0.0966 & 0.04 & 0.07 & 38.8 \\
\hline \multirow{3}{*}{$\begin{array}{l}\text { Particulate } \\
\text { COD }(\mathrm{mg} / \mathrm{mg} \\
\text { dry sample) }\end{array}$} & 1 & 3 & 0.1904 & 0.04779 & 0.02759 & 0.0717 & 0.3091 & 0.15 & 0.24 & 25.1 \\
\hline & 2 & 3 & 0.1897 & 0.03900 & 0.02252 & 0.0928 & 0.2866 & 0.16 & 0.23 & 20.6 \\
\hline & 3 & 3 & 0.1534 & 0.04969 & 0.02869 & 0.0300 & 0.2769 & 0.10 & 0.20 & 32.4 \\
\hline \multirow{3}{*}{$\begin{array}{l}\text { Moisture } \\
\text { Content (\% } \\
\text { wet sample) }\end{array}$} & 1 & 3 & 75.7102 & 6.84247 & 3.95050 & 58.7126 & 92.7078 & 68.66 & 82.32 & 9.0 \\
\hline & 2 & 3 & 75.9848 & 4.32280 & 2.49577 & 65.2464 & 86.7233 & 71.49 & 80.11 & 5.7 \\
\hline & 3 & 3 & 69.9685 & 9.25689 & 5.34447 & 46.9731 & 92.9639 & 60.55 & 79.05 & 13.2 \\
\hline \multirow{3}{*}{$\begin{array}{l}\text { Total Solids } \\
\text { (\% wet } \\
\text { sample) }\end{array}$} & 1 & 3 & 24.2898 & 6.84247 & 3.95050 & 7.2922 & 41.2874 & 17.68 & 31.34 & 28.2 \\
\hline & 2 & 3 & 24.0152 & 4.32280 & 2.49577 & 13.2767 & 34.7536 & 19.89 & 28.51 & 18.0 \\
\hline & 3 & 3 & 30.0315 & 9.25689 & 5.34447 & 7.0361 & 53.0269 & 20.95 & 39.45 & 30.8 \\
\hline \multirow{3}{*}{$\begin{array}{l}\text { Organic } \\
\text { Solids (\% dry } \\
\text { sample) }\end{array}$} & 1 & 3 & 76.1088 & 5.42864 & 3.13423 & 62.6234 & 89.5943 & 69.86 & 79.62 & 7.1 \\
\hline & 2 & 3 & 74.5096 & 3.56566 & 2.05864 & 65.6520 & 83.3672 & 70.55 & 77.47 & 4.8 \\
\hline & 3 & 3 & 70.8685 & 6.59300 & 3.80647 & 54.4905 & 87.2464 & 63.82 & 76.89 & 9.3 \\
\hline
\end{tabular}

$\mathrm{C}$ of $\mathrm{V}-$ Coefficient of Variation

The high ratio of particulate COD to soluble COD (3.1 - 3.3) suggests that most of the degradable COD present in the faeces were slowly degradable according to Wentzel et al. (1999) and Orhon and Çokgör (1997). This confirms the conclusions by Zavala et al. (2002), (2004) that slowly biodegradable organic matter accounts for $80 \%$ of human faeces. There was high variability among faecal samples (high $\mathrm{C}$ of $\mathrm{V}$ values) as the samples were obtained from public latrines. The total COD values obtained in this study were similar to those reported by Gaillard (2002) (0.57 $\mathrm{mg} / \mathrm{mg}$ dry sample) for fresh faeces and Nwaneri (2009) $(0.445 \mathrm{mg} / \mathrm{mg}$ dry sample), Nwaneri et al. (2008) (0.54 $\mathrm{mg} / \mathrm{mg}$ dry sample) for topmost layer of pits but slightly lower than those reported in literature for fresh faeces by Almeida et al. (1999) (1.38 mg/mg dry sample), Zavala et al. (2002) (1.45 mg/mg dry sample), Nwaneri (2009) $(1.11 \mathrm{mg} / \mathrm{mg}$ dry sample), Nwaneri et al. (2008) $(1.13 \mathrm{mg} / \mathrm{mg}$ dry sample) and Buckley et al. (2008) $(1.448 \mathrm{mg} / \mathrm{mg}$ dry sample). The total COD values for faeces sampled from the surface of pit obtained in this study compared with 
literature values for fresh faeces shows that although faeces at the surface is reported to be fresh by Nwaneri (2009), some amount of degradation occurs immediately fresh samples are added to the contents in the pit.

\section{Physico-chemical characteristics after different treatments with/without additives:-}

Figures 1, 2 and 3 show the physico-chemical characteristics (total COD, Moisture content and Organic solids) of fresh faeces after 30days treatment with/without additives (control, water, additives A, B and C). For all samples from the three pits, mean total COD ( $\mathrm{mg} / \mathrm{mg}$ dry sample) reduced across all the treatments $(0.135-0.166$ for control; $0.146-0.203$ for water reference; $0.166-0.208$ for additive A and $0.180-0.218$ for additive C) except additive $B$ which recorded an increase $(0.519-0.728)$ when compared with the fresh faeces before treatments $(0.203-0.250 \mathrm{mg} / \mathrm{mg}$ dry sample). A similar trend was observed for organic solids. The highest organic solids content was recorded in additive B (75 - 79\% dry sample) with the least occurring in the control (45-61\% dry sample).

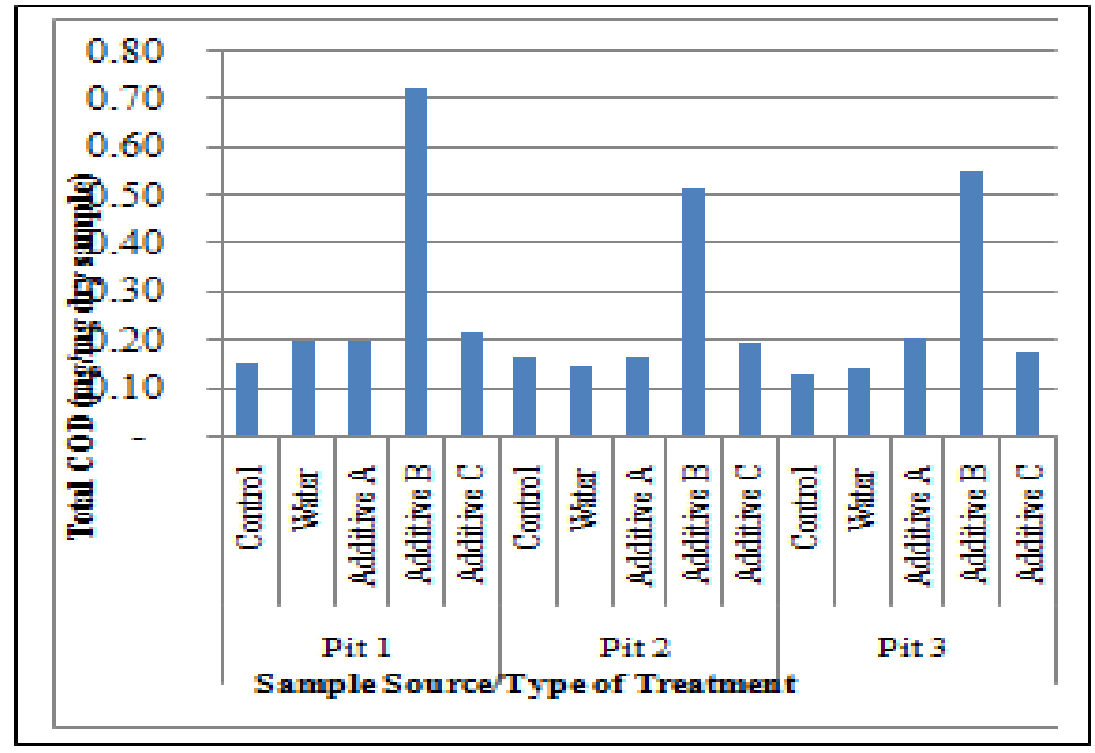

Figure 1:- Total COD of faeces after 30days treatment with/without additives.

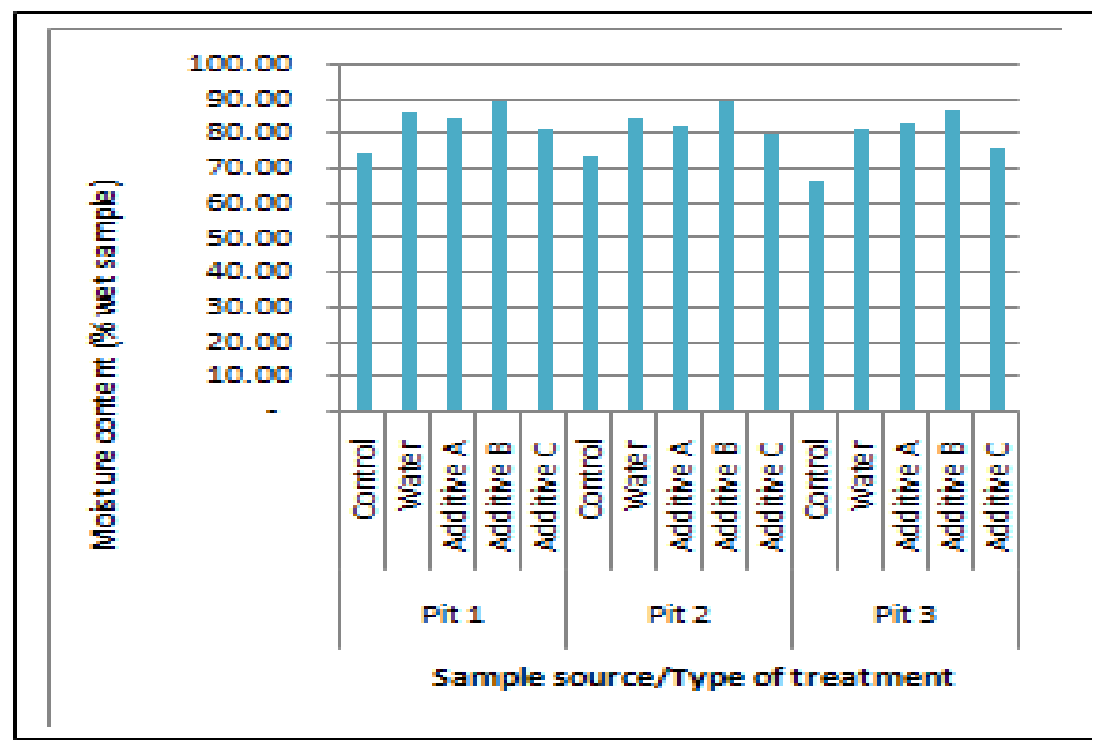

Figure 2:- Moisture content of faeces after 30days treatment with/without additives. 


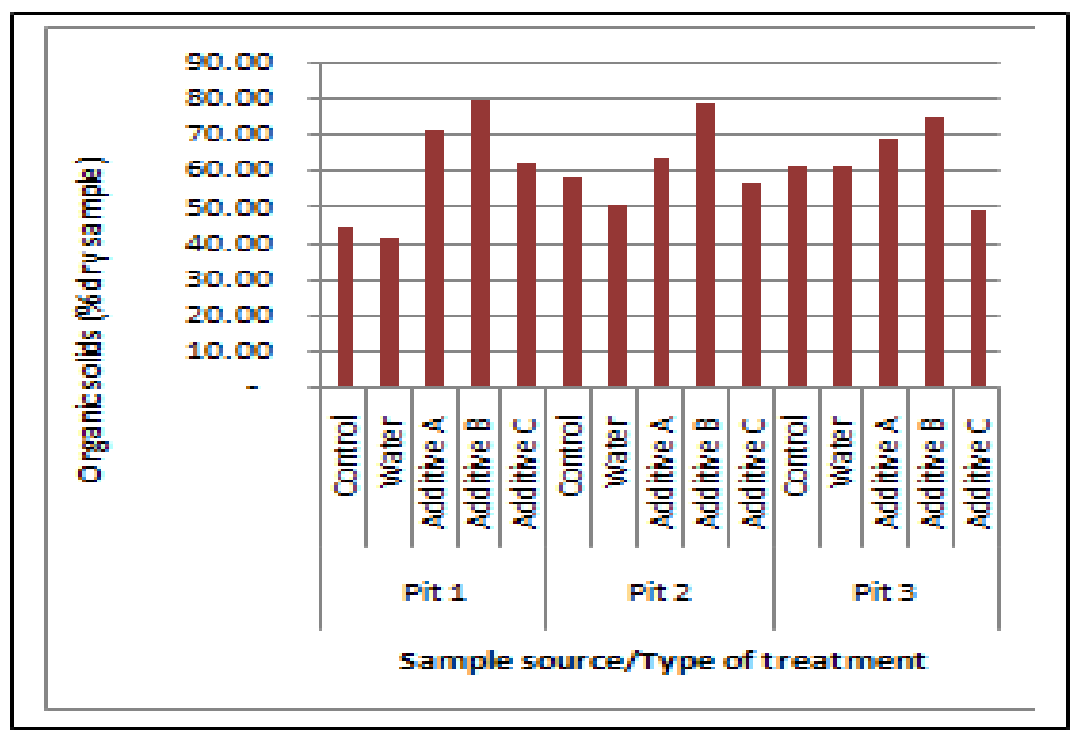

Figure 3:- Organic solids content of faeces after 30days treatment with/without additives.

With the exception of control, all the other treatments recorded an increase in moisture content with the highest occurring in additive B ( 86 - $89 \%$ wet sample). Additive B was a liquid therefore could have contributed to the high moisture content recorded after the 30days treatment. The high moisture content recorded in additive B with reduced total solids content (11-14\%wet sample against fresh faeces of $24-30 \%$ wet sample) could mean that additive B has converted about $20 \%$ of the total solids content to liquid. Additive B could be promising for reducing the content of pit latrines since in reality the liquid and soluble contents would infiltrate into the surrounding soil leaving the solids content. The other additives (A and $\mathrm{C}$ ) and water also caused a reduction in the total solids content of the faeces but the extent of reduction was low compared with that of additive B.

An ANOVA test performed on the various physico-chemical parameters measured shows with $95 \%$ confidence that there are significant differences in the mean COD, Moisture and Organic solids content after different types of treatment compared with the control $(\mathrm{p}<0.05)$. Additive $\mathrm{B}$ contributed highest to the differences in the mean physico-chemical characteristics after a Post-Hoc test. It could be inferred from the results that the various additives (A, B and C) did not decrease the total COD and organic solids of the faeces.

A pair sample t-test at $95 \%$ confidence level was conducted to compare the various physico-chemical characteristics measure after treatment with the control for all the three pits. The results showed that there was significant difference $(\mathrm{p}<0.05)$ in the mean total COD across all treatments when compared with the control and that the mean COD for all the other treatments were higher than that in the control. Similarly, when the mean organic solids contents across the other treatments were paired with the control, a significant difference $(\mathrm{p}<0.05)$ was found to exist between the means and that the mean organic solids content in the control were significantly lower than in the other treatments.

Effect of Additives on the Degradation rate of fresh faeces:-

The three additives (A, B and C) used in this study were applied to $200 \mathrm{~g}$ of pit latrine contents for a period of 30 days. The amount of mass loss for the three (3) pit latrines are presented in Figures 4, 5 and 6. 


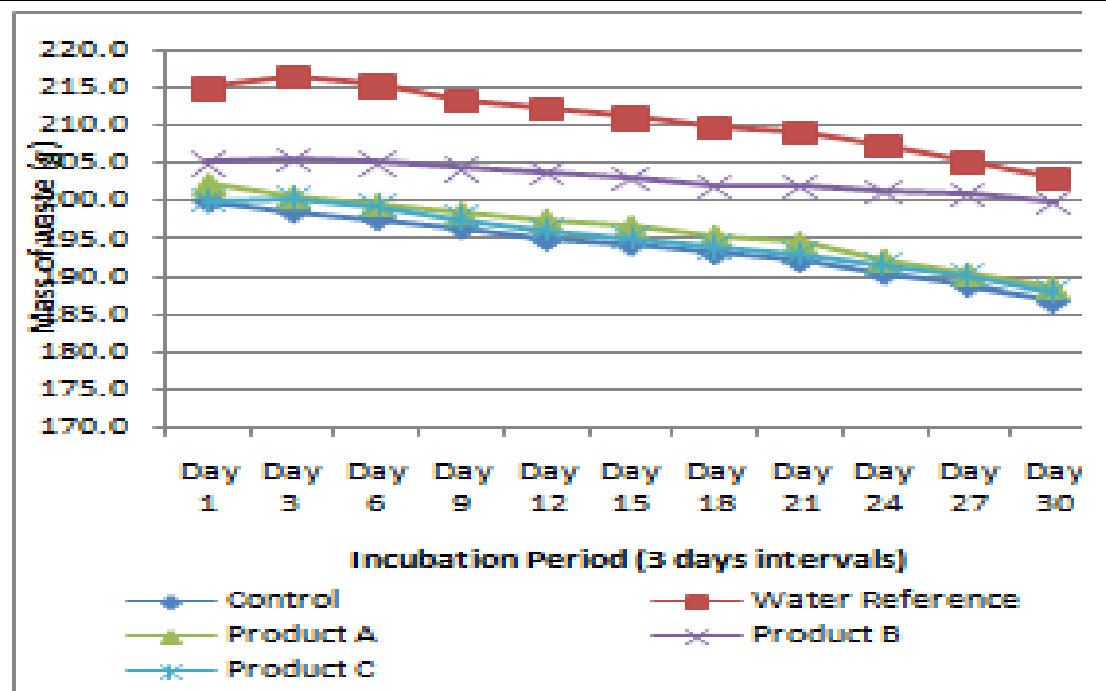

Figure 4:- Mass of contents in the honey jar over the 30day incubation period (Pit no. 1)

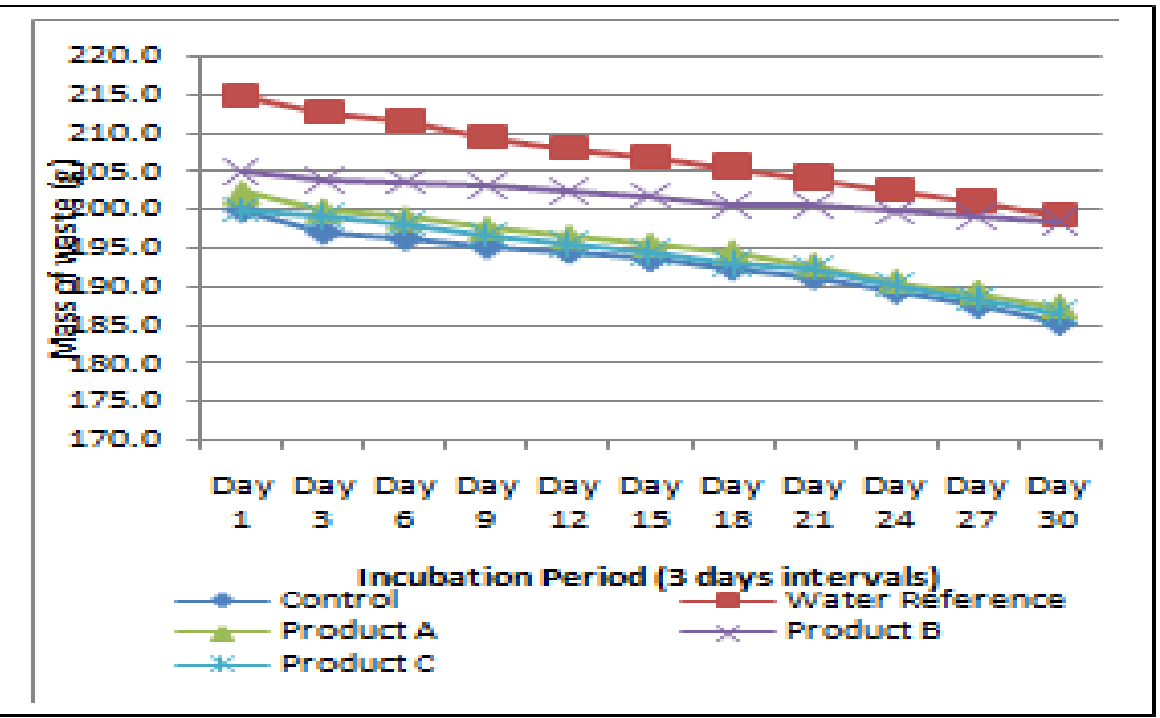

Figure 5:- Mass of contents in the honey jar over the 30day incubation period (Pit no. 2) 


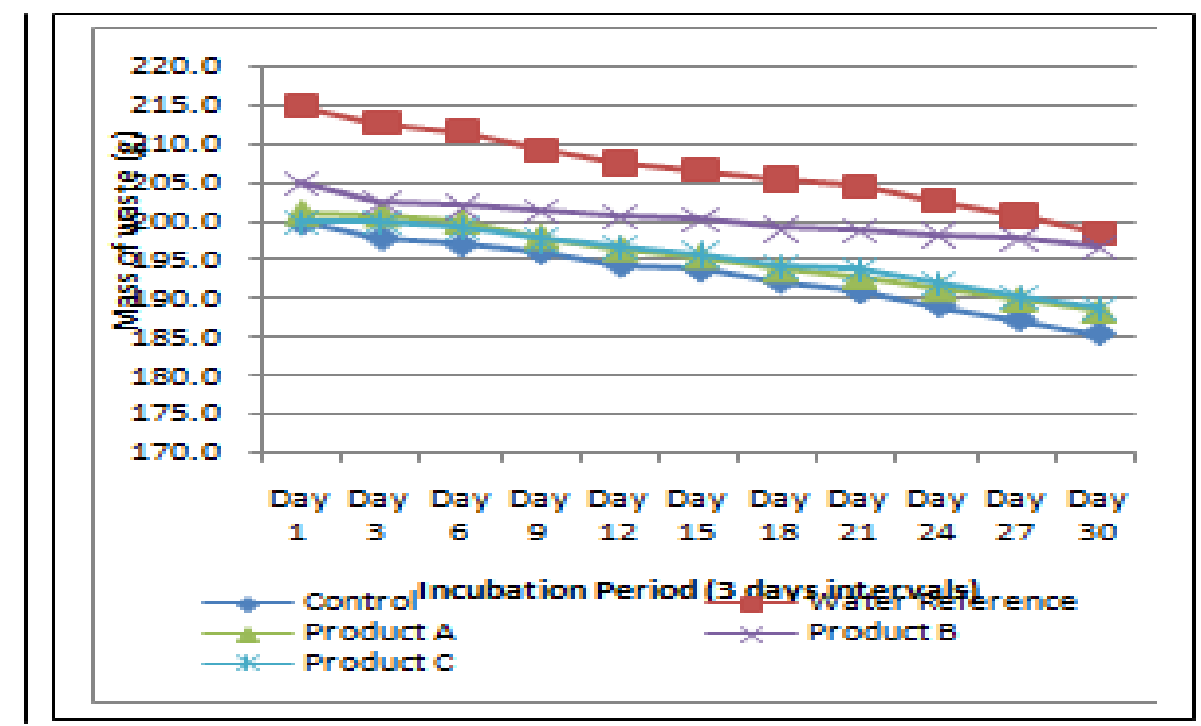

Figure 6:- Mass of contents in the honey jar over the 30day incubation period (Pit no. 3)

For all the samples from the three (3) pit latrines considered, the mass of waste in each unit decreased with time as shown in Figures 4.9, 4.10 and 4.11. The mass of waste in each unit decreased on the average from $200-186.6 \mathrm{~g}$ (Control), 215 - 203g (Water reference), 202.3 - 188.5g (Additive A), 205 - 199.8g (Additive B) and $200-188 \mathrm{~g}$ (Additive C) for samples from pit no. 1 and $200-185.5 \mathrm{~g}$ (Control), $215-199.3 \mathrm{~g}$ (Water reference), $202.3-187.3 \mathrm{~g}$ (Additive A), 205 - 198.3g (Additive B) and $200-186.7 \mathrm{~g}$ (Additive C) for samples from pit no. 2. With respect to samples from pit no. 3, the mass of waste in each unit decreased from $200-185.5 \mathrm{~g}$ (Control), $215-198.5 \mathrm{~g}$ (Water reference), 201.2 - 188.5g (Additive A), 205 - 196.8g (Additive B) and 200 - 188.8g (Additive C). All the three (3) additives were able to control flies and odour. Except for additive B which recorded a net mass loss between $2.6 \%$ and $4.1 \%$, all the other treatments recorded a net loss of $5.6 \%$ to $7.7 \%$ of their original mass for all types of latrines.

Though the rate of mass loss under aerobic conditions (30\%) is relatively small compared to anaerobic digestion (70\%) (Still \&Foxon, 2011), the rates recorded in this study for the control experiments $(6.6-7.3 \%)$ were far lower than expected. It is possible that the incubation period of 30days allowed for degradation was small and that given enough time, the percentage mass loss could increase. The high percentage of slowly degradable organic matter content (high ratio of particulate COD to soluble COD) obtained from the physico-chemical analysis (from Table 4) could also be a cause of the low mass loss rate recorded in the control samples. The low mass loss in the control could also be ascribed to the possible differences in environmental conditions within the pit and that in the test reactor (glass jar). Another probable reason for the low mass loss (less degradation) in the control sample is the negative effects of disinfectants used by caretakers of the pit latrines for controlling the odour and flies.

These disinfectants have detrimental effect on the life of microbial population present in the faeces. The low total COD values obtained from the physico-chemical analysis of the fresh faeces compared to literature values could contribute to the low amount of mass loss in the control samples. However, this may not be a very strong indication since the organic solids content recorded were high for all samples from the three pits. The mean rate of mass loss for samples from all the three (3) pit latrines is shown on Table 4.

Table 4:-Mean mass loss (g) for different treatments for the samples from the 3 pit latrines ( $\mathrm{N}=10$ for all data)

\begin{tabular}{|l|c|c|c|}
\hline Treatments & Pit no. 1 & Pit no. 2 & Pit no. 3 \\
\hline Control & $1.330 \pm 0.4218$ & $1.450 \pm 0.6786$ & $1.440 \pm 0.4648$ \\
\hline Water Reference & $1.210 \pm 1.0640$ & $1.580 \pm 0.3910$ & $1.650 \pm 0.6115$ \\
\hline Additive A & $1.370 \pm 0.5056$ & $1.500 \pm 0.4876$ & $1.260 \pm 0.4926$ \\
\hline Additive B & $0.530 \pm 0.4448$ & $0.670 \pm 0.3561$ & $0.830 \pm 0.6516$ \\
\hline Additive C & $1.210 \pm 0.6332$ & $1.320 \pm 0.4492$ & $1.120 \pm 0.6106$ \\
\hline
\end{tabular}


For pit no. 2 and pit no. 3 , the cumulative rate of mass loss over the 30 day incubation time were greatest in samples treated with water than the control samples and those treated with additives. The large variability in the mean mass lost for the various types of pit latrines with different treatments could be attributed to the differences in composition of contents in the various pit latrines. The composition of faeces differs from person to person due to different dietary intake (Torondel, 2010). This invariably leads to large heterogeneity in contents within and between different latrines. Buckley et al. (2008) reported that the heterogeneous nature of pit latrine contents could cause large variations in the composition of pit latrine contents making different pit latrine samples behave differently from one another.

To determine if the differences in the means of various treatments are statistically significant a paired sample t-test analysis was conducted at $95 \% \mathrm{CI}$ for the additives and water treatments against the control. The paired-sample ttest for samples from all the three (3) pit latrines revealed a similar trend. For all the pits, there was no statistically significant difference between the mean mass loss for water reference, additive $\mathrm{A}$ and $\mathrm{C}$ against the control (all $\mathrm{p}$ values > 0.05). The difference between the means of treatments with water, additive $\mathrm{A}$ and $\mathrm{C}$ could be due to error or chance. On the contrary, there was a significant difference between the mean mass loss rate for additive B for all the latrines $(\mathrm{p}<0.05)$. However the mean mass loss for the control samples $(\mathrm{M}=1.33, \mathrm{SD}=0.4218$ for pit no. 1; $\mathrm{M}=1.45, \mathrm{SD}=0.6786$ for pit no. $2 ; \mathrm{M}=1.44, \mathrm{SD}=0.4648$ for pit no. 3 ) were higher than those treated with additive $\mathrm{B}$ $(\mathrm{M}=0.53, \mathrm{SD}=0.4448$ for pit no. $1 ; \mathrm{M}=0.67, \mathrm{SD}=0.3561$ for pit no. $2 ; \mathrm{M}=0.83, \mathrm{SD}=0.6516$ for pit no. 3 ). The results of this study failed to provide evidence to support the claim that additives A, B and C can significantly improve the degradation rate of faecal samples. Even though additive B was able to reduce the solid content and increase the moisture content in the faeces (from Figure 2) the mass of waste lost was small and statistically insignificant probably because the liquid component resulting from the moisture increase did not leave the jar just as in the case of a pit latrine where the liquid components of the pit content infiltrate into the surrounding soil. The findings that additives $\mathrm{A}$ and $\mathrm{C}$ cannot increase the degradation rate of faeces are consistent with other findings on pit latrine additive studies in South Africa (Bakare et al., 2010; Buckley et al., 2008; Foxon et al., 2009) but contrary to research conducted in Uganda (Bwengye-Kahororo et al., 2013) and efficacy of household ash in improving degradation rate of faecal sludge (Agyei et al., 2011; Morgan, 2005). The failure of additive A (household ash) to improve the degradation rate could be attributed to the dosage applied. The dosage applied could be small compared to the dosage required to improve the degradation rate as noted by Agyei et al. (2011) and Morgan (2005).

According to Bakare et al. (2010) addition of water to the pit could help achieve increased rate of sludge degradation through two main effects; washing away soluble components of faeces or increasing the moisture content. Under field trials, Bakare et al. (2010) found that addition of water increased the rate of degradation but the finding was not observed under laboratory conditions. The result that addition of water does not increase the rate of degradation reported by Bakare et al. (2010) in a study under similar laboratory conditions was confirmed by this study.

\section{Conclusion:-}

From the results obtained the following conclusions are drawn.

1. There is large variability in the physical and chemical characteristics of pit contents between pits.

2. Public pit latrines are characterized by high content of slowly degradable organic matter.

3. Additives $\mathrm{A}$ and $\mathrm{C}$ administered in this study did not have any significant effect on the physico-chemical characteristics of the pit contents. However, additive B reduced the total solids content thereby increasing the moisture content of the faeces.

4. The mass of waste in each unit used for the pit latrine additives study decreased with time. However, additives A and $\mathrm{C}$ tested in this study did not have any significant effect on the mass of the waste. Additive $\mathrm{B}$ has the potential to increase the degradation rate of faeces but this was not conclusively tested. All the additives tested in this study were able to reduce odour and flies. 


\section{References:-}

1. Agyei, P. A., Awuah, E., \&Oduro-Kwarteng, S. (2011). Faecal sludge management in Madina, Ghana. Journal of Applied Technology in Environmental Sanitation, 1 (3): 239 - 249.

2. Almeida, M. C., Butler, D., \&Friedler, E. (1999). At-source domestic wastewater quality. Urban Water, 1: 49 -55 .

3. APHA, AWWA \& WEF (1999). Standard Methods for the Examination of Water and Wastewater (20th edition). American Public Health Association, American Water Works Association, Water Environment Federation.

4. Bakare, B. F., Nwaneri, C., Foxon, K. M., Brouckaert, C. J., Still, D., \& Buckley, C. A. (2010). Pit latrine additives: laboratory and field trials. Retrieved on June 10, 2013 from http://www.ewisa.co.za/literature/files/253_202\%20Bakare.pdf.

5. Bindoff, A. N. (2008). Investigation to determine the effectiveness of a commercially available pit latrine additive and the development and evaluation of a testing protocol. (MSc Thesis). Civil Engineering Programme, University of KwaZulu-Natal, Durban, South Africa.

6. Buckley, C. A., Foxon, K. M., Brouckaert, C. J., Rodda, N., Nwaneri, C., Balboni, E., Couderc, A., \&Magagna, D. (2008). Scientific Support for the Design and Operation of Ventilated Improved Pit Latrines (VIPS) and the Efficacy of Pit Latrine Additives. WRC Report No. TT 357/08. Water Research Commission, Pretoria, South Africa.

7. Bwengye-Kahororo, E., Lamsal, P., Ying, E. Jr., \&Sidoti, A. (2013). Uganda: Use of Effective microorganism (EMO) for stench elimination and sludge reduction in latrines. UNICEF Eastern \& Southern Africa Region Office (ESARO).

8. Doku, I. A. (2002). Anaerobic treatment of nightsoil and toilet sludge from on-site sanitation systems in Ghana. $\mathrm{PhD}$ thesis. The University of Leeds, School of Civil Engineering.

9. Foxon, K. M. (2007). Scientific Support for the Design and Operation of Ventilated Improved Pit Latrines (VIPS). WRC Report No. 1630/1/07. Water Research Commission, Pretoria, South Africa.

10. Foxon, K. M., Mkhize, S., Reddy, M., \& Buckley, C. A. (2009). Laboratory protocols for testing the efficacy of commercial pit latrine additives. Water SA, 35 (2): 228 - 235.

11. Jansen, G. J., Wilkinson, M. H. F., Deddens, B., \&Waaij, D. van der (1993). Characterization of human faecal flora by means of an improved fluoro-morphological method. Epidemiology of infectious diseases, 111: $265-272$.

12. Morgan, P. (2005). An ecological approach to sanitation in Africa - A compilation of experiences. EcosanRes, ed., Aquamor, Harare Zimbabwe.

13. Nwaneri, C. F. (2009). Physico-chemical characteristics and biodegradability of contents of ventilated improved pit latrines (VIPs) in eThekwini Municipality. (MSc Thesis). Faculty of Science and Agriculture, School of Biological and Conservation Sciences, University of KwaZulu-Natal, Durban, South Africa.

14. Nwaneri, C. F., Foxon, K. M., Bakare, B. F., \& Buckley, C. A. (2008). Biological degradation processes within a pit Latrine. Biennial Conference of the Water Institute of Southern Africa (WISA), Sun City, South Africa, 19th - 22nd May 2008.

15. Orhon, D., \&Cokgor, E. U. (1997). COD Fractionation in Wastewater Characterization - The State of the Art. Journal of Chemical Technology Biotechnology, 68: 283 - 293.

16. Stephen, A. M., \&Cummin, J. H. (1980). The microbial contribution to human faecal mass. Journal of Medical microbiology, 13: $45-56$.

17. Still, D., \&Foxon, K. (2011). Magic Muthis: Can biological additives make the problem go away? Faecal Sludge Management Seminar report, 14-15 March 2011, Durban, South Africa.

18. Strauss, M. (1985). Health Aspects of Nightsoil and Sludge use in Agriculture and Aquaculture - Part II: Pathogen Survival. Research Monograph No. 6.

19. Thye, Y. P., Templeton, M. R., \& Ali, M. (2009). Pit Latrine Emptying: Technologies, Challenges and Solutions. The Royal Academy of Engineering EWB-UK Research Conference, February 20, 2009.

20. Torondel, B. (2010). Literature Review: On-site sanitation waste characteristics. London School of Hygiene \& Tropical Medicine.

21. Wentzel, M. C., Mbewe, A., Lakay, M. T., \&Ekama, G. A. (1999). Batch test for characterization of the carbonaceous materials in municipal wastewaters. Water SA, 25 (3): 327 - 336.

22. Zavala, L. M. A., Funamizu, N., \&Takakuwa, T. (2002). Characterization of feces for describing the aerobic biodegradation of feces. Journal of Environmental Systems Engineering, VII-25 (720): 99 - 105.

23. Zavala, L. M. A., Funamizu, N., \&Takakuwa, T. (2004). Temperature effect on aerobic biodegradation of feces using sawdust as a matrix. Water Research, 38(9): 2406 - 2416. 